Revista Água Viva

ISSN 1678-7471

\title{
ENAMORARSE ANTES DE JUBILARSE: LAS CUATRO SOMBRAS DE MARTÍN SANTOMÉ
}

\section{FALLING IN LOVE BEFORE RETIRING: THE FOUR SHADES OF MARTÍN SANTOMÉ}

José Sarzi Amade ${ }^{1}$

Recebido em: 24 mai. 2020

Aceito em: 08 out. 2020

DOI 10.26512/aguaviva.v5i3.31752

RESUMEN: Este artículo analiza La tregua de Mario Benedetti. El estudio examina las diferentes fases o más bien los matices por los cuales pasó el personaje de Martín Santomé, protagonista de la obra, después de que un cambio inesperado trastornó su vida: la muerte de su amada Laura Avellaneda. El texto está dividido en cuatro partes. En la primera se alude al tema de la jubilación y a la obsesión de Martín Santomé con este momento. En la segunda, se estudia la importancia del personaje de Laura Avellaneda en la vida de Martín. En la tercera, se estudian los elementos que hacen que la relación entre ambos sea significativa. Finalmente, en la cuarta, se analiza la desolación que produce la muerte de la joven en la vida del protagonista.

Palabras-clave: La tregua. Mario Benedetti. Martín Santomé. Laura Avellaneda. Muerte. Jubilación. Enamoramiento.

ABSTRACT: This article analyzes La tregua of Mario Benedetti. The study examines the different phases or rather the shades for which Martín Santomé, main character of the novel, happened after an unexpected change upset his life: the death of his beloved Laura Avellaneda. The text is divided in four parts. The first one alludes to the topic of the retirement and how Martín Santomé faces this moment with a certain degree of obsession. The second one is focused on the importance that the character of Laura Avellaneda has in Martín's life. The third one studies the elements that make their affective relationship something significant for both of them. Finally, the fourth one examines the motif of desolation that emerges as a result of Avellaneda's death.

Keywords: La tregua. Mario Benedetti. Martín Santomé. Laura Avellaneda. Death. Retirement. Falling in love.

\footnotetext{
${ }^{1}$ Doctor (2016) en Lenguas Románicas por la Universidad de Aix-Marsella, José Sarzi Amade ha producido una tesis sobre las misiones capuchinas del siglo XVII en el Reino del Congo. Especialista en didáctica de lenguas extranjeras, también tiene una Maestría en esta disciplina por la Universidad de Artois (2018). Recientemente, se dedica a la literatura comparada y se unió, desde 2019, a la Universidad de St. John en Nueva York donde forma parte del Master en lengua y cultura española y es miembro de la asociación Sigma Delta Pi, Épsilon Kappa. Correo electrónico: josé.sarzi19@stjohns.edu
} 


\section{INTRODUCCIÓN}

Escrita en 1959 y publicada en 1960, La tregua de Mario Benedetti narra la historia del viudo Martín Santomé, quien, cercano a la jubilación, encuentra el amor y la felicidad que había buscado a lo largo de su vida. En la novela se describen su rutina de vida, su relación con sus hijos, sus encuentros con amigos, alusiones a su esposa difunta, a su trabajo rutinario, sus reflexiones sobre Dios o la existencia y, por supuesto, a Laura Avellaneda, quien logra darle un nuevo sentido a su cotidianidad hasta que la muerte de la joven pone fin a la felicidad del protagonista.

Como puede notarse, la historia de Martín, protagonista de La tregua, bien podría reenviar a la de un Dino, personaje principal de La noia (El tedio) de Moravia, pues las dos novelas tienen varios motivos en común. En primer lugar, fueron publicadas el mismo año, en 1960. En segundo lugar, tienen como leitmotiv el tema común del déboire amoroso y vacío existencial. Sin embargo, el personaje benedettiano se aleja del moraviano debido a un aspecto importante: Martín es una persona de edad madura.

El tema de la jubilación puede ser obsesivo para personas que durante su vida sufrieron el peso de la vida salarial, la repetición, así como ciertas tragedias familiares. Sobrevienen entonces las preguntas de orden existencial: ¿Qué será de mí después de este día fatídico? ¿Qué hacer del poco tiempo que me queda por vivir? ¿Habrá todavía un sitio para mí? ¿Quién me cerrará los ojos? ¿Cómo emplear mi tiempo, con quién, con qué?

Todas estas incertidumbres están presentes en La tregua. Su narrador, Martín Santomé, nos expresa, por medio de las notas fragmentarias de su diario: sus sentimientos, sus estados de ánimo cotidianos, y sobre todo el relato de la aventura romántica que vivió en el año de su jubilación.

En este ensayo trataré de aprehender las diferentes fases o más bien los matices por los cuales pasó este personaje después de que un cambio inesperado trastornó su vida. 


\section{CONTRA LAS PREVISIONES DEMOSCÓPICAS DE LA EXISTENCIA}

L'histoire d'amour est le tribut que l'amoureux doit payer au monde pour se réconcilier avec lui ; elle est faussement réduite à une maladie hippocratique, qui naît, monte, fait souffrir et passe (BARTHES, 1977, p. 11)2.

A la edad de Martín Santomé, las ocasiones de encontrar el amor son muy pocas, por lo menos en la opinión que comúnmente se tiene y lo que se observa en la sociedad. Aunque la posibilidad de enamorarse disminuye con la edad, esta sigue siendo buscada por la gente en general, y por Santomé en particular, a pesar de las convenciones y las múltiples extrapolaciones sobre el matrimonio, el amor, etc. $^{3}$

Como ya se mencionó, las primeras líneas del diario están dominadas por el tema de la jubilación, cuya edad legal es 50 años. Es la obsesión de Martín Santomé, contador uruguayo de 49 años que vive en Montevideo. A partir del 11 de febrero, inicia su cuenta regresiva a la fecha fatídica: 6 meses y 28 días. Desde hace 5 años, él sueña con eso, absorbido por la rutina del trabajo, un hogar que se aleja cada vez más de él (sus tres niños son grandes y van independizándose poco a poco del domicilio familiar), amistades que en realidad no existen, y sobre todo por los lejanos y dolorosos recuerdos de la pérdida de su esposa Isabel (él tenía 28 años y ella, 25 cuando murió como consecuencia de un parto). Todo parece fluir inexorablemente, inevitablemente, y el hábito se ha convertido incluso en su única razón de ser: "Hoy fue un día feliz, sólo rutina" (BENEDETTI, 1960, p. 13-15). Todos sus días se parecen a los domingos angustiosos, propicios al suicidio (p. 31-32).

La evocación de la jubilación y de su proximidad se mezcla en Santomé con el torpor de la existencia y la sensación de agonía por la aproximación lenta de la muerte, pero también con la última luz de esperanza de cambio:

Cuando me jubile, tal vez lo mejor sea abandonarme al ocio, a una especie de modorra compensatoria, a fin de que los nervios, los músculos, a energía, se relajen de a poco y se acostumbren a bien morir. Pero no. Hay momentos en que tengo y mantengo la lujosa esperanza de que el ocio sea algo pleno, rico, la última oportunidad de encontrarme a mí mismo (BENEDETTI, 1960, p.1819).

\footnotetext{
2 "La historia de amor es el tributo que el amante debe pagar al mundo para reconciliarse con él; se reduce falsamente a una enfermedad hipocrática, que nace, se levanta, causa sufrimiento y pasa." (N. del T.)

${ }^{3}$ Como ejemplo, me refiero a la obra de Charles Fourier y su Théorie des quatre mouvements amoureux (1808), en la que denuncia la falsedad del amor civilizado, clasificable, según él, en 64 especies de adulterio. Fourier diseccionó las irregularidades del matrimonio, dándoles categorías casi científicas. Él distingue cuatro estados esenciales que caracterizan la unión entre dos personas: la amistad y la ambición (modo mayor) y el amor y la familia (modo menor), mientras que él aborrece dos géneros abyectos: el amor egoísta y la poligamia furtiva.
} 
Es el 27 de febrero la fecha en que se produce algo inesperado. En efecto, siete nuevos empleados se incorporan a la oficina de contadores, y entre ellos, Laura Avellaneda, una joven de 24 años (23).

\section{EL ESTADO NACIENTE}

El estado naciente (del enamoramiento o de los movimientos) tiene la extraordinaria propiedad de rehacer el pasado. [...] El estado naciente es una proliferación de signos. En este proceso en que se ven envueltos el pasado y el presente también está comprometida la naturaleza. La lluvia o el sol, la forma de una nube, enriquecen su valor. [...] El amor produce una geografía sacra del mundo. [...] Si el tiempo de la felicidad del estado naciente es el presente eterno, la conjunción de estos instantes de eternidad constituye un año litúrgico con sus recurrencias sacras (ALBERONI, 1996, p.30, 40-42).

La presencia de Laura actúa sobre Santomé como un perturbador, una razón para examinar progresivamente el cuerpo de esta joven que trabaja delante de él. A veces una mirada, se fija en sus piernas, a veces una sonrisa furtiva "algo es algo", piensa él. ${ }^{4}$ Pero ya un sentimiento confuso está germinando en el corazón de Santomé, un luego efecto hipnótico que le desvía la atención. Esta chica lo atormenta: le cuenta los lunares en el antebrazo, entrevé su cuerpo bajo su ropa (BENEDETTI, 1960, p.28, 32-33, 47-48). Lo más difícil entonces es declararse, revelarle sus sentimientos, a pesar de esta diferencia de edad y la consiguiente improbabilidad que deriva de eso. Martín busca entonces huidas, en los brazos de una vieja prostituta (36-38), en el remordimiento de la postergación, él que conoció a Isabel en "pleno auge del deseo" y que, desde hace veinte años, tiene los sentimientos congelados. Incluso aunque Avellaneda le dice que tiene novio (46). Él ahora está guiado por el amor naciente y ya no puede moderarse, porque no es un simple plan lo que lo motiva, sino algo más, él cree ${ }^{5}$. Según Alberoni, él está a punto de vivir un nuevo «nosotros colectivo», el movimiento más pequeño y colectivo que sea dado, hecho solamente de dos personas (amante/amado) (ALBERONI, 1996, p. 9-14).

\footnotetext{
${ }^{4}$ Tal vez sea necesario recordar la versión que Platón da en El Banquete sobre el origen del amor. Fruto de un deslice entre un Poros (recurso) embriagado y una Penia (pobreza) aprovechada. De hecho, Eros habría heredado de sus padres, este carácter ambivalente, imperfecto en esencia, a la vez hermoso y poderoso, pero también indigente y evanescente; de ahí el sentimiento contrastado del enamoramiento.

${ }^{5}$ Allí también, hay que matizar, recordando que el enamoramiento proceda del desarreglo de los senes, un estado de confusión, de pérdida de vigilancia. Arthur Schopenhauer no transige sobre este principio, totalmente movido, según él, por el deseo sexual, el cual no debe ser confundido con otra cosa: "Todo enamoramiento, por etéreo que afecte ser, sumerge en realidad todas sus raíces en el instinto sexual, y hasta no es otra cosa más que este instinto especializado, determinado, individualizado por completo." (apud, 1851, p. 8).
} 


\section{LA DECLARACIÓN DE LOS SENTIMIENTOS Y EL REALISMO EN AMOR}

[...] la déclaration s'inscrit dans la structure de l'événement. Vous avez d'abord une rencontre. [...] l'amour commence par le caractère absolument contingent et hasardeux de la rencontre. [...] C'est un problème quasi métaphysique très compliqué: comment un pur hasard, au départ, va-t-il devenir le point d'appui d'une construction de vérité? (BADIOU, 2009$, p. 24$)^{6}$

A fuer de «actividad» sentimental, el amor se diferencia de los sentimientos inertes, como alegría o tristeza. [...] el amor es de suyo, constitutivamente, un acto transitivo en que nos afanamos hacia lo que amamos. Quietos, a cien leguas del objeto, y aun sin que pensemos en él, si lo amamos, estaremos emanando hacia él una fluencia indefinible, de carácter afirmativo y cálido. (ORTEGA Y GASSET, 1945, p. 41)

Con el fin de hacer de su sueño una realidad, hay que dejar el mutismo, rompiendo el silencio ¿Santomé debe expresar esto con severidad, franquicia, "fallutería" - sic - (BENEDETTI, 1960, p. 66-67)? Todavía no sabe nada al respecto, pero después de un período de vacilación, decide confesarle lo inconfesable, el 17 de mayo:

Mire, Avellaneda, es muy posible que lo que le voy a decir le parezca una locura. Si es así, me lo dice nomás. Pero no quiero andar con rodeos: creo que estoy enamorado de usted. [...] A mi edad y a su edad, lo más lógico hubiera sido que me callase la boca; pero creo que, de todos modos, era un homenaje que le debía. Yo no voy a exigir nada. Si usted, ahora o mañana o cuando sea, me dice basta, no se habla más del asunto y tan amigos (BENEDETTI, 1960, p. 74-75).

A esta oferta y proposición que parecían tan difíciles de formular para Santomé, Laura Avellaneda está apenas sorprendida. Estas respuestas lacónicas son pruebas que ella ya está al tanto ("ya lo sabía") y que la atracción es reciproca ("Usted me gusta”). Hay que decir que las cosas están claras entre él y ella, transparentes. No es una aventura, sino algo más que la amistad, un equilibrio entre la

\footnotetext{
6 “[...] la declaración es parte de la estructura del evento. Primero tiene un encuentro. [...] el amor comienza con el carácter absolutamente contingente y arriesgado del encuentro. [...] Es un problema casi metafísico muy complicado ¿Cómo la pura casualidad, al principio, se convertirá en la base de una construcción de la verdad?” (N. del T.).
} 
necesidad de ser amado, sin dificultar la libertad del amante ${ }^{7}$. Los dos se acercan e intercambian el primer beso el 7 de junio (88-90). Santomé ha vuelto a la felicidad y se siente rejuvenecido, no quiere perder la vitalidad y la esperanza que esta relación le devuelve. Para conseguirlo refleja, mide e incluso teoriza las condiciones para que de este romance no sea aburrido para su pareja.

No quiero perjudicarla ni quiero perjudicarme (primera equidistancia); no quiero que nuestro vínculo arrastre consigo la absurda situación de un noviazgo tirando a matrimonio, ni tampoco que adquiera el matiz de un programa vulgar y silvestre (segunda equidistancia); no quiero que el futuro me condene a ser un viejo despreciado por una mujer en la plenitud de sus sentidos, ni tampoco que, por temor a ese futuro, quede yo al margen de un presente como éste, tan atractivo e incanjeable (tercera equidistancia); no quiero (cuarta y última equidistancia) que vayamos rodando de amueblada en amueblada, ni tampoco que fundemos un Hogar con mayúscula (BENEDETTI, 1960, p. 90-91).

Todo esto es posible, porque precavidamente Martín Santomé alquila un piso con el fin de encontrarse allí con su amante. A partir del 28 de junio, no son más que uno:

\begin{abstract}
Al fin. A las siete y media salí de la oficina y fui al apartamento. Ella había llegado antes, había abierto con su llave y se había instalado. Cuando llegué me recibió alegremente, sin inhibiciones, otra vez con beso. Comimos. Hablamos. Reímos. Hicimos el amor. Todo estuvo tan bien, que no vale la pena escribirlo. Estoy rezando: "Que dure", y para presionar Dios voy a tocar madera sin patas. (BENEDETTI, 1960, p.104)
\end{abstract}

Desde entonces, Santomé no dejará de buscar estos momentos de eternidad, porque es este rejuvenecimiento del corazón lo que necesita. La felicidad está ahora en el punto de encuentro y nada

\footnotetext{
${ }^{7}$ Con su texto Amores, Ovidio, maestro en el ars amandi, ya había anunciado todo: "Rígido esposo que pusiste un guardián a tu juvenil compañera, son inútiles tus precauciones: la mujer se defiende con su propia virtud. Aquella es casta que no lo es por miedo, y la que no peca por falta de ocasión, es como si pecara. Si tu vigilancia preserva el cuerpo, su mente se goza en el adulterio, y nadie alcanza a vigilar a la que rechaza los guardianes. Aunque asegures bien los cerrojos, no aprisionarás el pensamiento, y después de despedir a todos, el adúltero se quedará dentro de casa. El que puede faltar sin miedo, falta menos, y sus apetitos languidecen por la misma libertad que goza. óyeme, cesa de irritar el vicio con la persecución; lo vencerás más fácilmente con una obsequiosa complacencia. Yo vi poco ha galopar tan presto como el rayo un corcel indómito, que se revolvía contra el freno, y detenerse de súbito así que cesó la opresión y sintió flojas las riendas sobre las espesas crines. Apetecemos siempre lo vedadlo y deseamos lo que se nos niega, como el enfermo ansía el agua que se le prohíbe." (Libro III, 4).
} 
parece perturbar este estado de gracia: "Nunca en mi vida, ni con Isabel ni con nadie, me sentí tan cerca de la gloria" (p.162).

\title{
4. A MODO DE CONCLUSIÓN: SÉNECA TENÍA RAZÓN
}

\begin{abstract}
Además, son tres los tipos de vida entre los que se suele buscar cuál es el mejor: uno se consagra al placer, otro a la contemplación, el tercero a la acción. (SÉNECA, 63, Sobre el ocio, p.162)
\end{abstract}

Pero la jubilación y su fecha simbólica del 13 de septiembre, va a precipitar el destino de la pareja. Esta fecha suena el toque de muerte de la desgracia, ya que unos días después, Laura cae enferma. Ella no se presenta más al trabajo. Santomé no sospecha nada, al contrario, cree que su ausencia es propicia para él, porque piensa pedirla en matrimonio tan pronto como regresa. La tragedia es completa cuando, el 23 de septiembre, él aprende por teléfono la absurdidad de la muerte de su querida: la gripe se la llevó. Su pena es inmensa (BENEDETTI, 1960, p.171-174).

La interrupción de su diario está probablemente relacionada con el peso del luto de Laura. El 17 de enero, vuelven sus notas. Ahora, dejan espacio para la nostalgia, la melancolía y los recuerdos dolorosos de lo que Martín Santomé entiende ahora metafísicamente: esta historia de amor fue su tregua, antes de su jubilación, o sea por extensión, antes de su inexorable muerte.

Es evidente que Dios me concedió un destino oscuro. Ni siquiera cruel. Simplemente oscuro. Es evidente que me concedió una tregua. Al principio, me resistí a creer que eso pudiera ser la felicidad. Me resistí con todas mis fuerzas, después me di por vencido y lo creí, Pero no era la felicidad, era sólo una tregua. Ahora estoy otra vez metido en mi destino. Y es más oscuro que antes mucho más. (BENEDETTI, 1960, p.185)

El diario termina el 28 de febrero, fecha que corresponde al último día de trabajo de Santomé. Encontró una fotografía de Avellaneda entre sus cajas, y un sentimiento de amargura y culpa lo invadió. También sabe que a partir de mañana va a romper con la rutina de su trabajo y que no sabe cómo utilizar el tiempo que le queda hasta su muerte (BENEDETTI, 1960, p. 186).

No tenemos escaso tiempo, sino que perdemos mucho. Nuestra vida es suficientemente larga y se nos ha dado en abundancia para la realización de las más altas empresas, si se invierte bien toda entera; pero en cuanto se disipa a través del lujo y la apatía, en cuanto no se dedica a nada bueno, cuando por 
fin nos reclama nuestro último trance nos percatamos de que ya ha transcurrido la vida que no comprendimos que corría. Así es: no recibimos una vida corta, sino que nos la hacemos, y no somos indigentes de ella, sino dilapidadores. [...] Todo el mundo acelera su vida y se esfuerza por su ansia del futuro, por su hastío del presente. Por el contrario, el que no deja ningún momento sin dedicarlo a sus intereses, el que organiza todos sus días como si fueran el último, ni ansía el mañana ni lo teme [...] En tres etapas se divide la vida: la que ha sido, la que es, la que va a ser. De ellas, la que estamos pasando es breve, la que vamos a pasar, incierta, la que hemos pasado, segura; ésta es, pues, en la que la suerte ha perdido sus derechos, la que no se puede sujetar de nuevo al capricho de nadie. (SÉNECA, 189, Sobre la brevedad de la vida, p. 194-196)

Con estas lúcidas reflexiones de Séneca, no condenemos a nadie, en cambio, ponemos estas frases como consuelo. Quería ser amado en su vejez, pero fue la juventud misma la que desapareció (la muerte de Laura). El final que ofrece Benedetti en su novela, no es tal vez lo que más esperaba la razón. La muerte burlona, implacable y absurda se llevó a Laura en su plena juventud. Se esperaba más bien la muerte de Santomé, que estaba en proceso de retirarse de un mundo, de su mundo.

\section{REFERÊNCIAS}

ALBERONI, Francesco. Enamoramiento y Amor. Trad. Juana Bignozzi. Barcelona: Gedisa editorial. Sexta edición, [1979] 1996.

BADIOU, Alain. Éloge de l’amour. Paris: Flammarion, 2009.

BARTHES, Roland. Fragments d'un discours amoureux. Paris: Éditions du Seuil, 1977.

BENEDETTI, Mario. La tregua. Madrid: Literatura Alfaguara, [1960] 1983.

FOURIER, Charles. Théorie des quatre mouvements et des destinées générales suivi du Nouveau Monde amoureux (1808). Introduction et édition établie par Simone Debout-Oleszkiewicz. Paris: Collection l'Écart absolu, 1998.

ORTEGA Y GASSET, José. Estudios sobre el amor. Madrid: Revista de Occidente, 1945.

OVIDIO. Los amores. Trad. Germán Salinas. En: Líricos y elegíacos latinos. Madrid: Librería de Perlado, Páez y Cía., 1913-1914.

SCHOPENHAUER, Arthur. Metafísica del amor [Parerga und Paralipomena (Fragmentos)]. 1851.

SÉNECA. Diálogos. [Dialogorum Libri XII, 63], Edición electrónica <lectulandia.com>, 2016. 